BENTHAM OPEN
CrossMark
Content list available at: www.benthamopen.com/TOORTHJ/
DOI: $10.2174 / 1874325001610010559$

RESEARCH ARTICLE

\title{
Predictors of Bone Status by Quantitative Ultrasound Measurements in a Mountain Village in Japan
}

Tsuyoshi Tajika*, Atsushi Yamamoto, Takashi Ohsawa, Noboru Oya, Haku Iizuka and Kenji Takagishi

Department of Orthopaedic Surgery, Gunma University Graduate School of Medicine, Gunma, Japan, 3-39-22, Showamachi, Maebashi, Gunma 371-8511, Japan

Received: July 24, 2016

Revised: October 18, 2016

Accepted: October 20, 2016

\section{Abstract:}

\section{Background:}

It seems to be important to recognize predictors of bone health condition in Japanese super-aged society. The purpose of this study was to investigate predictors of the speed of sound (SOS) of calcaneus by quantitative ultrasound measurements of mountain village residents.

\section{Materials and Methods:}

Medical examinations were conducted on 214 participants (69 men, 145 women; average age of 63.6 years). Each had completed a self-administered questionnaire including items such as gender, dominant hand, occupation, and history of smoking and drinking alcohol, experience of falls, and the EuroQol-5-dimensions-3-level Japanese version and a 25-question geriatric locomotive function scale proposed by the Japanese Orthopaedic Association. Bilateral grip and key pinch strength were measured. The SOS of calcaneus was assessed using ultrasound bone densitometry. Body composition was measured using a multi-frequency segmental body composition analyzer. Spearman's rank correlation coefficient was calculated to elucidate the relation between SOS and evaluation items. Stepwise logistic regression was used to identify predictors of SOS using the investigated factors as explanatory variables. P values of $<.05$ were regarded as statistically significant.

\section{Results:}

Significant positive correlation was found between the SOS and dominant and non-dominant grip and key pinch strength and Euro index and QOL VAS in all participants. In stepwise logistic regression, non-dominant key pinch $(\beta$ coefficient $=0.27, p=.022)$ and Euro QOL VAS ( $\beta$ coefficient $=0.24, \mathrm{p}=.0001$ ) were predictors of calcaneal SOS for all participants.

\section{Conclusion:}

Key pinch strength and Euro QOL VAS assessment might be useful to predict calcaneal SOS in the general population.

Keywords: Bone Quality, Calcaneus, Handgrip, Key Pinch, Osteoporosis, Quality of Life.

\section{INTRODUCTION}

In Japan, the percentage of the elderly population (age $\geq 65$ years) reached $25 \%$ in 2013 . That ratio is expected to exceed $30 \%$ in 2025 and to reach $39.9 \%$ in 2060 [1]. Given increasing trends of general population aging in Japan, osteoporosis looms as a major health problem. The estimated number of patients in Japan with osteoporosis was 12.8

\footnotetext{
* Address correspondence to this author at the Department of Orthopaedic Surgery, Gunma University Graduate School of Medicine, 3-39-22, Showa-machi, Maebashi, Gunma 371-8511, Japan; Tel: 81-27-220-8269; Fax: 81-27-220-8270; E-mail: tajika@gunma-u.ac.jp
} 
million in 2012 [2]. Osteoporosis-related fracture, particularly hip fracture, is associated strongly with mortality and increasingly higher costs of health care. The incidence of hip fractures in Asia is estimated to increase by $520 \%$ during 1990-2050, implying that in 2050, $45 \%$ of all hip fractures that occur worldwide will take place in Asia, compared with $26 \%$ in 1990 [3]. To prevent the progress of osteoporosis, it is important to check bone status regularly and to elucidate the related factors of bone health condition in the general population. Quantitative ultrasound (QUS) assessment of the calcaneus rapidly provides a risk assessment of osteoporosis [4]. Earlier studies have demonstrated a significant relation between active lifestyles and higher bone mineral density (BMD) and higher quantitative ultrasonometry measurements [5]. In a preliminary study, we evaluated the association between calcaneal SOS and bilateral grip strength and key pinch strength in the same area. Results of age-adjusted analysis show significant association between osteoporosis and bilateral grip strength and key pinch strength [6]. The Japanese Orthopaedic Association (JOA) has proposed a new pathological concept of 'locomotive syndrome' to designate a condition in high-risk populations with musculoskeletal diseases including osteoporosis for people who might require nursing care services [7]. Earlier studies have also demonstrated a close relation between bone status measured by QUS and quality of life (QOL) in postmenopausal women [8]. Nevertheless, little is known about the QUS parameters and health-related QOL in general populations. This study was designed to assess the association between osteoporosis defined by the speed of sound (SOS) of calcaneus using quantitative ultrasound measurements, to assess the effects of multiple factors, and to evaluate the predictors of SOS of calcaneus in mountain village residents.

\section{MATERIALS AND METHODS}

Local medical examinations intended for early detection of cancer and for prevention of lifestyle-related diseases are conducted regularly for residents of a mountain village in Japan, where agroforestry and tourism are the main industries. For this study, 214 people (69 men, 145 women; average 63.6 years of age, range 29-90) were selected randomly. Each had completed a self-administered questionnaire with items related to gender, dominant hand, heaviness of labor (no job, light, intermediate, and heavy), falling history during the year preceding this examination, smoking and drinking habits, and personal history. The exclusion criteria of this study were (1) participants who had a prior operation in bilateral upper extremities, (2) participants who had pain of bilateral upper extremities, and (3) participants who took medications that affect bone metabolism, such as bisphosphonates and glucocorticoids. After they had been informed of the study protocol and had been told that their data would be published, all participants gave their consent to participate in this study. This study was approved by the regional ethics board.

\section{Locomotive Function Assessment}

All participants had completed the 25-question Geriatric Locomotive Functional Scale (GLFS-25). Seichi et al. developed it to detect Japanese individuals presenting high-risk conditions for care service because of problems of locomotive organs [9]. The GLFS-25 is a self-administered comprehensive measure that consists of 25 items, including 4 questions related to pain during the prior month, 16 questions related to activities of daily living during the prior month, 3 questions related to social functions, and 2 questions related to mental health conditions during the prior month. These 25 questions are graded with five-point scales from no impairment ( 0 points) to severe impairment (4 points). The points are summed to produce a total score (minimum 0, maximum 100). A higher total score is related with worse locomotive function. Seiichi et al. verified the reliability and validity of the GLFS-25 [9].

\section{Quality of Life (QOL) Assessment}

EuroQol-5-Dimension-3Level Japanese version (EQ-5D-3L) and EuroQol-Visual Analog Scale Japanese version (EQ-VAS) are used to assess health-related QOL. The EuroQol-5D-3L assesses the following five dimensions: mobility, self-care, usual activities, pain/discomfort, and anxiety/depression [10]. The EuroQol-5D-3L (Japanese version) was validated by Tsuchiya et al. as having evaluation capacity equivalent to the original (ver. 1) [11]. The EQVAS records a respondent's self-rated health on a vertical, visual analog scale with labeled endpoints.

\section{Anthropometric Measurements}

Height was measured using a digital height meter (A\&D Corp., Tokyo, Japan). The body composition was measured using a multi-frequency segmental body composition analyzer (MC780U; Tanita Corp., Tokyo, Japan). The body mass, body mass index, total muscle mass, fat mass, fat free mass, and body fat ratio were measured. 


\section{Grip and Key Pinch Strength Measurements}

A digital dynamometer (Takei Scientific Instruments Co., Tokyo, Japan) was used to measure grip strength. A pinch gauge (MG-4320NC pinch gauge; B \& L) was used to measure the key pinch of both sides. Grip testing was conducted using the standardized position recommended by the American Society of Hand Therapists. Participants were seated with the shoulder in adduction and neutral rotation, elbow flexed at $90^{\circ}$, forearm in a neutral position, and the wrist between $0^{\circ}$ and $30^{\circ}$ of extension and $0^{\circ}$ and $15^{\circ}$ of ulnar deviation. Key pinch testing was performed with the shoulder, elbow, forearm, and wrist in a neutral position. Key pinch is the thumb pad to the lateral aspect of middle phalanx of index finger. For each grip and pinch test, three measurements were performed on the bilateral side. All tests were administered by a single orthopedic surgeon.

\section{Quantitative Ultrasound Assessment of Calcaneus}

The SOS of the calcaneus bone of right side was measured using an ultrasound bone densitometer (Furuno Electric Co. Ltd., Nishinomiya, Japan). This device has a unique sensor to compensate for the participant's heel temperature to provide accurate SOS measurements. The T-score is calculated from the manufacturer-specific SOS reference population database. This machine was calibrated with a physical phantom. All measurements were taken by the same orthopedic surgeon.

\section{Statistical Analyses}

Descriptive statistics were calculated for all direct measurements. Differences in the values of the indices were assessed for significance using analysis of variance for comparisons among multiple groups. Scheffé's test was used for pairs of age groups.

Spearman's rank correlation coefficient was calculated to elucidate the relation between SOS and age, height, weight, body mass index (BMI), dominant and non-dominant grip and key pinch strength, anthropometry variables, GLFS-25 score, Euro QOL index score, and Euro QOL VAS. Univariate and multivariate logistic analyses were used to evaluate statistical significance for participants with osteoporosis and without osteoporosis using age, height, weight, BMI, gender, dominant and non-dominant grip and key pinch strength, anthropometry variables, GLFS-25 score, EuroQOL index score, EuroQOL VAS, heaviness of labor (no job, light, intermediate, and heavy), the experience of a fragility related fracture, falling history during one year preceding this examination, smoking and drinking habits, and personal history as explanatory variables. Osteoporosis was defined as a T-score below $-2.5 \times$ standard deviation (SD), according to the WHO definition. Stepwise linear regression was used to identify the SOS predictors using age, height, weight, BMI, gender, dominant and non-dominant grip and key pinch strength, anthropometry variables, GLFS-25 score, EuroQOL index score, EuroQOL VAS as explanatory variables. All $P$ values of $<.05$ were inferred as statistically significant.

\section{RESULTS}

Tables 1 and $\mathbf{2}$ present characteristics of the participants, including anthropometry variables, SOS, bilateral grip and key pinch strength, GLFS-25 score, EuroQOL index, and VAS.

Table 1. Characteristics of anthropometric measurements and SOS of participants to age clusters.

\begin{tabular}{|c|c|c|c|c|c|c|c|c|c|}
\hline Age group & $n$ & Height (cm) & Weight (kg) & $\begin{array}{c}\text { Body mass } \\
\text { index }\left(\mathrm{g} / \mathrm{cm}^{2}\right)\end{array}$ & $\begin{array}{c}\text { Fat free } \\
\text { mass }(\mathrm{kg})\end{array}$ & $\begin{array}{c}\text { Total muscle } \\
\text { mass }(\mathrm{kg})\end{array}$ & $\begin{array}{r}\text { Total fat } \\
\text { mass }(\mathrm{kg})\end{array}$ & $\begin{array}{c}\text { Pct. } \\
\text { body fat (\%) }\end{array}$ & $\begin{array}{c}\text { Calcaneus speed of } \\
\text { sound }(\mathrm{m} / \mathrm{s})\end{array}$ \\
\hline \multicolumn{10}{|l|}{ Men } \\
\hline \multicolumn{10}{|l|}{ Age } \\
\hline$<50$ & 9 & $171.9(8.1)$ & $70.3(8.5)$ & $24.0(2.6)$ & $58.3(4.9)$ & $55.2(4.6)$ & $12.6(5.8)$ & $17.4(6.4)$ & $1503.2(21.8)$ \\
\hline $50-59$ & 10 & $169.4(2.2)$ & $67.3(4.9)$ & $23.6(1.6)$ & $55.7(4.0)$ & $52.8(3.8)$ & $12.2(4.1)$ & $17.7(5.1)$ & $1504.8(25.7)$ \\
\hline $60-69$ & 18 & $166.7(6.7)$ & $68.6(10.2)$ & $24.4(2.9)$ & $54.6(5.3)$ & $51.8(5.0)$ & $14.0(6.0)$ & $19.7(5.3)$ & $1490.6(27.6)$ \\
\hline $70-79$ & 21 & $159.9(4.3)^{\mathrm{a}, \mathrm{b}, \mathrm{c}}$ & $59.9(6.5)^{\mathrm{a}, \mathrm{c}}$ & $23.7(2.0)$ & $47.8(4.3)^{\mathrm{a}, \mathrm{b}, \mathrm{c}}$ & $45.4(4.1)^{\mathrm{a}, \mathrm{b}, \mathrm{c}}$ & $12.8(4.3)$ & $20.8(5.3)$ & $1510.5(34.8)$ \\
\hline $80-$ & 11 & $160.1(3.8)^{\mathrm{a}, \mathrm{b}}$ & $56.7(6.4)^{\mathrm{a}, \mathrm{c}}$ & $22.2(2.2)$ & $46.9(5.6)^{\mathrm{a}, \mathrm{b}, \mathrm{c}}$ & $44.4(5.3)^{\mathrm{a}, \mathrm{b}, \mathrm{c}}$ & $10.1(5.2)$ & $17.5(8.0)$ & $1510.5(44.7)$ \\
\hline Total & 69 & $164.6(7.1)$ & $64.1(9.1)$ & $23.7(2.3)$ & $51.3(6.3)$ & $48.6(6.0)$ & $12.6(5.0)$ & $19.8(5.9)$ & $1503.5(32.4)$ \\
\hline \multicolumn{10}{|l|}{ Women } \\
\hline$<50$ & 24 & $157.0(5.3)$ & $53.6(6.8)$ & $21.9(2.9)$ & $38.7(3.0)$ & $36.5(2.7)$ & $15.3(5.1)$ & $27.7(6.3)$ & $1497.0(27.5)$ \\
\hline $50-59$ & 31 & $155.0(6.7)$ & $56.6(11.0)$ & $23.6(4.4)$ & $38.4(3.8)$ & $36.2(3.5)$ & $18.5(8.5)$ & $31.2(7.9)$ & $1494.0(27.6)$ \\
\hline
\end{tabular}


(Table $\square$ ) contd.....

(Table $\square$ ) contd.....
\begin{tabular}{|l|c|c|c|c|c|c|c|c|c|}
\hline Age group & $\boldsymbol{n}$ & Height $(\mathbf{c m})$ & Weight $(\mathbf{k g})$ & $\begin{array}{c}\text { Body mass } \\
\text { index }\left(\mathbf{g} / \mathbf{c m}^{2}\right)\end{array}$ & $\begin{array}{c}\text { Fat free } \\
\text { mass }(\mathbf{k g})\end{array}$ & $\begin{array}{c}\text { Total muscle } \\
\text { mass }(\mathbf{k g})\end{array}$ & $\begin{array}{c}\text { Total fat } \\
\text { mass }(\mathbf{k g})\end{array}$ & $\begin{array}{c}\text { Pct. } \\
\text { balcaneus speed of } \\
\text { sound }(\mathbf{m} / \mathbf{s})\end{array}$ \\
\hline $60-69$ & 45 & $152.0(6.4)$ & $52.9(8.9)$ & $23.1(3.3)$ & $36.8(3.6)$ & $34.7(3.3)$ & $16.4(6.5)$ & $29.8(7.3)$ \\
\hline $70-79$ & 33 & $149.6(5.8)^{\mathrm{a}, \mathrm{b}}$ & $52.0(8.7)$ & $23.4(3.5)$ & $35.3(3.1)^{\mathrm{a}, \mathrm{b}}$ & $33.4(2.9)^{\mathrm{a}, \mathrm{b}}$ & $16.6(7.2)$ & $30.8(8.1)$ \\
\hline $80-$ & 12 & $147.6(8.9)^{\mathrm{a}, \mathrm{b}}$ & $48.1(6.9)$ & $23.5(2.9)$ & $31.8(2.6)^{\mathrm{a}, \mathrm{b}, \mathrm{c}}$ & $30.2(2.4)^{\mathrm{a}, \mathrm{b}, \mathrm{c}}$ & $16.4(5.2)$ & $1499.8(33.0)$ \\
\hline Total & 145 & $152.7(7.0)$ & $53.1(9.0)$ & $23.1(3.5)$ & $36.7(3.8)$ & $34.6(3.5)$ & $16.7(6.8)$ & $33.3(6.2)$ \\
\hline
\end{tabular}

Mean values are shown with the standard deviation.

SD: standard deviation

a. Significantly different $(p<.05)$ from values of the younger-than-50-years-old age group

b. Significantly different $(p<.05)$ from values of the 50 s age group

c. Significantly different $(p<.05)$ from values of the 60 s age group

d. Significantly different $(p<.05)$ from values of the 70 s age group

Table 2. Characteristics of grip and key pinch strength and Locomo 25 score and EuroQOL of participants according to age clusters.

\begin{tabular}{|c|c|c|c|c|c|c|c|c|}
\hline Age group & $\begin{array}{c}\text { Total } \\
\text { examined member }\end{array}$ & \begin{tabular}{|c|} 
Dominant \\
handgrip (kg)
\end{tabular} & \begin{tabular}{|c|}
$\begin{array}{c}\text { Non- } \\
\text { dominant } \\
\text { handgrip (kg) }\end{array}$ \\
\end{tabular} & $\begin{array}{c}\text { Dominant } \\
\text { key pinch (kg) }\end{array}$ & $\begin{array}{c}\text { Non- } \\
\text { dominant } \\
\text { key pinch (kg) }\end{array}$ & \begin{tabular}{|c|} 
Locomo25 \\
score (point)
\end{tabular} & $\begin{array}{c}\text { EuroQOL } \\
\text { index score }\end{array}$ & $\begin{array}{l}\text { EuroQOL } \\
\text { VAS (mm) }\end{array}$ \\
\hline \multicolumn{9}{|l|}{ Men } \\
\hline \multicolumn{9}{|l|}{ Age } \\
\hline$<50$ & 9 & $22.5(6.1)$ & $25.4(10.7)$ & $8.2(2.7)$ & $7.5(2.6)$ & $6.3(5.8)$ & $0.85(0.18)$ & $65.0(29.0)$ \\
\hline $50-59$ & 10 & $22.6(4.0)$ & $22.3(5.2)$ & $6.5(1.1)$ & $6.8(1.9)$ & $5.1(5.5)$ & $0.78(0.32)$ & $75.5(22.1)$ \\
\hline $60-69$ & 18 & $23.9(7.1)$ & $22.1(8.1)$ & $6.9(1.8)$ & $6.8(1.9)$ & $5.2(5.0)$ & $0.79(0.14)$ & $57.5(21.8)$ \\
\hline $70-79$ & 21 & $25.9(6.9)$ & $25.6(8.6)$ & $7.9(1.9)$ & $7.6(1.9)$ & $8.1(7.5)$ & $0.80(0.18)$ & $63.8(25.8)$ \\
\hline $80-$ & 11 & $25.8(8.3)$ & $27.7(12.2)$ & $8.2(2.3)$ & $8.0(2.3)$ & $10.6(12.4)$ & $0.74(0.36)$ & $72.0(20.5)$ \\
\hline Total & 69 & $24.5(6.7)$ & $24.6(9.0)$ & $7.5(2.1)$ & $7.3(2.1)$ & $7.0(7.5)$ & $0.79(0.23)$ & $65.1(24.0)$ \\
\hline \multicolumn{9}{|l|}{ Women } \\
\hline$<50$ & 24 & $23.1(5.0)$ & $22.1(6.7)$ & $7.0(1.9)$ & $6.6(1.8)$ & $3.3(3.3)$ & $0.86(0.21)$ & $68.0(23.6)$ \\
\hline 50-59 & 31 & $27.8(8.6)$ & $27.4(7.1)$ & $7.8(2.2)$ & $7.5(2.1)$ & $9.1(11.8)$ & $0.89(0.11)$ & $75.1(19.2)$ \\
\hline $60-69$ & 45 & $25.7(6.4)$ & $24.6(8.2)$ & $7.6(2.2)$ & $7.6(2.3)$ & $10.6(11.3)$ & $0.80(0.26)$ & $64.3(24.7)$ \\
\hline 70-79 & 33 & $24.9(6.7)$ & $24.4(7.8)$ & $7.5(2.1)$ & $7.2(2.1)$ & $12.8(14.3)$ & $0.80(0.16)$ & $68.8(21.6)$ \\
\hline $80-$ & 12 & $27.0(7.3)$ & $26.3(7.3)$ & $8.1(2.4)$ & $7.8(2.1)$ & $28.9(15.8)^{\mathrm{a}, \mathrm{b}, \mathrm{c}, \mathrm{d}}$ & $0.82(0.13)$ & $55.3(18.5)$ \\
\hline Total & 145 & $25.7(7.9)$ & $24.9(7.9)$ & $7.6(2.1)$ & $7.3(2.1)$ & $11.0(13.1)$ & \begin{tabular}{|l|}
$0.83(0.19)$ \\
\end{tabular} & $67.6(22.6)$ \\
\hline
\end{tabular}

Mean values are shown with the standard deviation.

SD: standard deviation

a. Significantly different $(p<.05)$ from values of the younger-than-50-years-old age group

b. Significantly different $(p<.05)$ from values of the 50 s age group

c. Significantly different $(p<.05)$ from values of the 60s age group

d. Significantly different $(p<.05)$ from values of the 70 s age group

The SOS of men showed significant positive correlation with dominant and non-dominant grip and key pinch strength and Euro QOL VAS. Positive correlation was found for the SOS of women between dominant and nondominant grip and key pinch strength and Euro index and QOL VAS. For all participants, significant positive correlation was found between the SOS and dominant and non-dominant grip and key pinch strength and Euro index and QOL VAS (Table 3).

We divided the participants into two populations according to their calcaneal SOS based on the T-score calculated from the manufacturer-specific SOS reference population database: osteoporosis $(n=63)$ and non-osteoporosis $(n=151)$. Table 4 presents the relation between osteoporosis and each anthropometric factor and background factor of activity of daily life. Significant association was found by univariate analysis between dominant and non-dominant handgrip and key pinch strength and the Euro QOL index and VAS and osteoporosis. Moreover, using multiple logistic regression analysis, significant association was found between non-dominant handgrip strength and osteoporosis (Table 4).

Table 3. Correlation between calcaneus SOS and anthropometric and grip, key pinch strength and Locomo25, EuroQOL data.

\begin{tabular}{|c|c|c|c|c|c|c|}
\hline Variable & Men & $p$ value & Women & $p$ value & All participants & $p$ value \\
\hline Age (years) & 0.05 & .68 & 0.07 & .37 & 0.07 & .28 \\
\hline
\end{tabular}


(Table $\llbracket$ ) contd......

\begin{tabular}{|c|c|c|c|c|c|c|}
\hline Variable & Men & $p$ value & Women & $p$ value & All participants & $p$ value \\
\hline Weight (kg) & -0.15 & .23 & -0.03 & .75 & -0.02 & .78 \\
\hline Height $(\mathrm{cm})$ & -0.14 & .27 & -0.10 & .24 & -0.04 & .61 \\
\hline $\operatorname{BMI}\left(\mathrm{kg} / \mathrm{m}^{2}\right)$ & -0.11 & .35 & -0.07 & .42 & -0.09 & .32 \\
\hline Fat free mass $(\mathrm{kg})$ & -0.19 & .10 & 0.05 & .59 & 0.05 & .44 \\
\hline Total muscle mass $(\mathrm{kg})$ & -0.19 & .10 & 0.04 & .60 & 0.05 & .43 \\
\hline Total fat mass $(\mathrm{kg})$ & 0.01 & .91 & -0.07 & .43 & -0.08 & .26 \\
\hline Percent of body fat (\%) & 0.07 & .57 & -0.11 & .19 & -0.12 & .08 \\
\hline Dominant handgrip (kg) & 0.43 & .0002 & 0.38 & .00 & 0.39 & .00 \\
\hline Non-dominant handgrip (kg) & 0.59 & .00 & 0.41 & .00 & 0.46 & .00 \\
\hline Dominant key pinch (kg) & 0.56 & .00 & 0.41 & .00 & 0.45 & .00 \\
\hline Non-dominant key pinch $(\mathrm{kg})$ & 0.55 & .00 & 0.39 & .00 & 0.44 & .00 \\
\hline Locomo 25 score & 0.10 & .42 & -0.12 & .16 & -0.06 & .41 \\
\hline EuroQOL index score & 0.16 & .19 & 0.20 & .02 & 0.18 & .0092 \\
\hline EuroQOL VAS (mm) & 0.31 & .01 & 0.22 & .007 & 0.25 & .0002 \\
\hline
\end{tabular}

Table 4. Data of study participants with and without osteoporosis.

\begin{tabular}{|c|c|c|c|c|c|c|}
\hline Variable & $\begin{array}{c}\text { Non- } \\
\text { Osteoporosis } \\
(n=151)\end{array}$ & $\begin{array}{c}\text { Osteoporosis } \\
\quad(n=63)\end{array}$ & $\begin{array}{l}\text { Crude odds ratio } \\
(95 \% \mathrm{CI})\end{array}$ & $p$ & $\begin{array}{l}\text { Adjusted odds ratio } \\
(95 \% \mathrm{CI})\end{array}$ & $p$ \\
\hline Age (years) & $64.1(13.5)$ & $62.2(14.0)$ & $0.98(0.96-1.01)$ & .35 & $0.99(0.96-1.02)$ & .56 \\
\hline Weight (kg) & $56.2(10.1)$ & $58.1(11.2)$ & $1.01(0.99-1.05)$ & .23 & $1.01(0.74-1.38)$ & .96 \\
\hline Height $(\mathrm{cm})$ & $156.1(10.1)$ & $157.4(9.7)$ & $1.02(0.98-1.05)$ & .33 & $1.04(0.94-1.14)$ & .44 \\
\hline $\operatorname{BMI}\left(\mathrm{kg} / \mathrm{m}^{2}\right)$ & $23.2(3.3)$ & $23.7(3.0)$ & $1.05(0.96-1.14)$ & .33 & $1.09(0.71-1.66)$ & .71 \\
\hline \multicolumn{7}{|l|}{ Gender } \\
\hline Men (n) & 50 & 19 & 1 & .67 & 1 & .21 \\
\hline Women (n) & 101 & 44 & $1.15(0.61-2.70)$ & & $5.22(0.40-68.1)$ & \\
\hline Fat free mass $(\mathrm{kg})$ & $41.5(8.2)$ & $42.2(9.5)$ & $1.01(0.98-1.04)$ & .56 & $0.09(0.002-5.26)$ & .24 \\
\hline Total muscle mass $(\mathrm{kg})$ & $39.2(7.8)$ & $39.9(9.1)$ & $1.01(0.98-1.04)$ & .56 & $13.9(0.18-1093.3)$ & .24 \\
\hline Total fat mass $(\mathrm{kg})$ & $15.1(6.5)$ & $16.1(7.0)$ & $1.02(0.98-1.07)$ & .29 & $0.89(0.57-1.40)$ & .64 \\
\hline Percent of body fat (\%) & $26.4(8.6)$ & $27.5(9.0)$ & $1.02(0.98-1.05)$ & .38 & $1.07(0.86-1.34)$ & .57 \\
\hline Dominant handgrip (kg) & $26.7(6.5)$ & $21.9(6.0)$ & $0.87(0.82-0.93)$ & .00 & $1.01(0.91-1.13)$ & .80 \\
\hline Non-dominant handgrip (kg) & $26.9(7.9)$ & $19.7(7.0)$ & $0.86(0.81-0.91)$ & .00 & $0.84(0.74-0.95)$ & .006 \\
\hline Dominant key pinch $(\mathrm{kg})$ & $8.1(2.1)$ & $6.5(1.9)$ & $0.64(0.53-0.78)$ & .00 & $1.05(0.68-1.64)$ & .81 \\
\hline Non-dominant key pinch $(\mathrm{kg})$ & $7.8(2.1)$ & $6.3(1.8)$ & $0.64(0.53-0.78)$ & .00 & $1.03(0.65-1.63)$ & .90 \\
\hline Locomo 25 score & $9.1(10.7)$ & $11.5(14.2)$ & $1.02(0.99-1.04)$ & .18 & $1.01(0.98-1.05)$ & .52 \\
\hline EuroQOL index score & $0.85(0.18)$ & $0.77(0.30)$ & $0.20(0.05-0.79)$ & .021 & $0.50(0.08-3.39)$ & .48 \\
\hline EuroQOL VAS (mm) & $69.3(22.4)$ & $60.9(23.9)$ & $0.98(0.97-0.99)$ & .02 & $0.99(0.97-1.004)$ & .12 \\
\hline \multicolumn{7}{|l|}{ History of falls/ prior one year } \\
\hline No $(n)$ & 117 & 47 & 1 & & 1 & \\
\hline Yes $(n)$ & 34 & 16 & $1.17(0.59-2.32)$ & .65 & $1.24(0.49-3.10)$. & .65 \\
\hline \multicolumn{7}{|l|}{ Experience of fragility facture } \\
\hline No $(n)$ & 129 & 53 & 1 & & 1 & .75 \\
\hline Yes $(n)$ & 22 & 10 & $1.10(0.49-2.49)$ & 0.81 & $0.84(0.29-2.48)$ & \\
\hline \multicolumn{7}{|l|}{ Heaviness of labor } \\
\hline No job & 11 & 7 & 1 & & 1 & \\
\hline Light & 44 & 17 & 0.55 & .29 & $1.11(0.27-4.51)$ & .88 \\
\hline Intermediate & 76 & 22 & 0.41 & .1 & $0.58(0.15-2.24)$ & .42 \\
\hline Heavy & 20 & 17 & 1.21 & .74 & $1.51(0.36-6.40)$ & .58 \\
\hline \multicolumn{7}{|l|}{ Smoking history } \\
\hline No smoking & 135 & 53 & 1 & & 1 & \\
\hline Smoking & 16 & 10 & $1.59(0.68-3.73)$ & .28 & $1.66(0.57-4.84)$ & .35 \\
\hline \multicolumn{7}{|l|}{ Alcohol history } \\
\hline No alcohol & 121 & 55 & 1 & & 1 & \\
\hline
\end{tabular}


(Table $\square$ ) contd.....

\begin{tabular}{|c|c|c|c|c|c|c|}
\hline Variable & $\begin{array}{c}\text { Non- } \\
\text { Osteoporosis } \\
(n=151) \\
\end{array}$ & $\begin{array}{l}\text { Osteoporosis } \\
\quad(n=63)\end{array}$ & $\begin{array}{c}\text { Crude odds ratio } \\
(95 \% \mathrm{CI})\end{array}$ & $p$ & $\begin{array}{c}\text { Adjusted odds ratio } \\
(95 \% \mathrm{CI})\end{array}$ & $p$ \\
\hline Alcohol & 30 & 8 & $0.59(0.25-1.36)$ & .21 & $0.31(0.09-1.04)$ & .06 \\
\hline
\end{tabular}

Mean values are shown with the standard deviation in parentheses. Odds ratios were calculated using univariate and multivariate analyses. A one-unit change in the explanation variable increases the odds of having osteoporosis by a factor of the odds ratio.

$\mathrm{CI}$, confidence interval

In men, stepwise linear regression analysis revealed that non-dominant handgrip, drinking (alcohol) history and Euro QOL VAS were significant contributors to increased SOS. The coefficient of determination $\left(R^{2}\right)$ for this stepwise linear regression model was 0.52 . In women, stepwise linear regression analysis revealed that non-dominant key pinch and Euro QOL VAS were significant contributors to increased SOS. For this $R^{2}$ was 0.27 . In all participants, nondominant key pinch and Euro QOL VAS were predictors of calcaneal SOS. For this stepwise linear regression model, $R^{2}$ was 0.30 (Table 5).

Table 5. Predictors of calcaneal SOS.

\begin{tabular}{|l|c|c|c|c|c|c|c|c|}
\hline \multicolumn{2}{|c|}{ Men } & \multicolumn{2}{c|}{ Women } & \multicolumn{2}{c|}{ All participants } \\
\hline Predictors & $\begin{array}{c}\boldsymbol{\beta} \\
\text { coeff. }\end{array}$ & $\boldsymbol{p}$ & Predictors & $\begin{array}{c}\boldsymbol{\beta} \\
\text { coeff. }\end{array}$ & $\boldsymbol{p}$ & Predictors & $\begin{array}{c}\boldsymbol{\beta} \\
\text { coeff. }\end{array}$ & $\boldsymbol{p}$ \\
\hline Non-dominant handgrip & 0.59 & .012 & Non-dominant key pinch & 0.26 & .024 & Non-dominant key pinch & 0.27 & .021 \\
\hline Alcohol history & 0.21 & .006 & Euro QOL VAS & 0.23 & .003 & Euro QOL VAS & 0.24 & .0001 \\
\hline Euro QOL VAS & 0.26 & .028 & & & & & & \\
\hline
\end{tabular}

\section{DISCUSSION}

QUS offers some parameters for the information related to bone structures and bone quality that are independent of BMD by the QUS models. SOS, which is one parameter, has been used as an indicator of bone elasticity. The ultrasound bone densitometry that we used has been validated [12] and used in earlier studies [13,14]. It is particularly interesting that in our study, no significant difference was found in SOS of calcaneus between each age group in men and women. The employment rate among all participants was $92 \%$. The employment rate in participants aged $\geq 80$ years was $87 \%$. This point demands special mention. The degree of high activity in old people might affect the lack of difference of SOS found in each generation.

Earlier studies investigated the relation between body anthropometry and calcaneal SOS. However, their results were not definitive $[14,15]$. Chin et al. reported age, height, weight, body fat percentage, and physical activity as predictors of calcaneal SOS in a multiple regression analysis of 687 Malaysian men [14]. However, Babaroutesi et al. reported no significant relation between weight and BMI with calcaneal SOS on the male Greek population [15]. Results of regression analysis showed that anthropometric factors exerted no significant influence on calcaneal SOS in men or women, or in all participants. The reason might be that the small sample size influenced the statistical power to assess the anthropometric factors and calcaneal SOS.

Handgrip strength assessment has been used as a reliable index for whole body muscle strength [16]. Yoshimura et al. conducted a large-scale population-based cohort survey to investigate the reference value of physical performance in Japan. This report described that hand grip strength declined significantly with age in a population aged over 40 years [17]. Furthermore, the association between handgrip strength and BMD was demonstrated by earlier studies [18, 19]. Sinaki et al. reported a significant positive relation between hand grip strengths and BMD of lumbar vertebrae and proximal femur in healthy premenopausal Caucasian women [18]. Aydin et al. reported a significant positive correlation between the hand grip strength of dominant and non-dominant sides and BMD of forearm in patients with various rheumatic complaints [19]. It appeared that not only site-specific, but also systemic BMD was associated with handgrip strength. We investigated the associations between normative grip strength and key pinch strength in high school students in an earlier study [20]. Results showed that the key pinch strength is a significant predictor of grip strength on the dominant side. Few reports of the literature have described studies of the relation between hand intrinsic muscle power and bone quality [6]. In the present study, we investigated the relation not only between handgrip, and key pinch strength, anthropometric variables, the degree of activity of daily life and the degree of satisfaction of QOL and calcaneal SOS. In our study, calcaneal SOS was correlated positively with the bilateral handgrip and key pinch strength. Moreover, non-dominant handgrip strength was associated significantly with osteoporosis, as found through QUS in multiple logistic regression analysis. In stepwise linear regression, the non-dominant key pinch strength was found to have a significant association with calcaneal SOS in men and women, and for all participants. The frequency 
of use of the non-dominant hand is lower than that of the dominant hand in daily life. Extrinsic and intrinsic muscle power on the non-dominant-hand-side might therefore reflect the influence of the physical activity condition better than that on dominant side. Our results suggest that muscle strengthening of extrinsic and intrinsic muscle is an important indicator of bone quality.

The osteogenic response appears to saturate after external loading [21]. Reportedly, physical activity is associated with calcaneal SOS. Chin et al. found that International Physical Activity Questionnaire scores were correlated significantly with calcaneal SOS in Malaysian men [15]. We investigated the relation between physical activity condition assessed by GLFS25 and calcaneal SOS. The relation was not significant. Muramoto et al. reported that weak negative correlation was found between the physical activity condition and each of the calcaneal SOS and GLFS 25 scores in women, but no correlation was found for men [22]. Additional studies must elucidate the association between two variables.

Few reports of the literature have described the relation between falls and QUS parameters. Ou et al. reported that broadband under attenuation (BUA) derived from calcaneal QUS in women and SOS derived from radial QUS in men are independently associated with falls [23]. Actually, BUA has been used as an indicator of bone stiffness. However, our study found no significant association with osteoporosis determined by calcaneal SOS and fall history. The difference in results might derive from the assessments of bone quality, which were done using different QUS devices and bone sites assessed using QUS.

An earlier study found a significant relation with calcaneal QUS parameters and fragility fractures. Lee et al. evaluated the risk factors for fractures of the proximal humerus among 6901 white women of over 75 years old in the prospective study [24]. They found that the measure of the SOS at the calcaneus was able to predict humeral fractures independently of BMD and that the strength of the association between SOS and fracture is similar to that observed with BMD. In our study, no significant association was found between the experience of fragility fractures and osteoporosis. Furthermore, the experience of fragility fractures was no predictor of calcaneal SOS. Subjects with fragility fractures were significantly older than those without fragility fractures (fragility fracture group: Mean age (SD) 70.1 (10.9), No fragility fracture group: Mean age (SD) 62.4 (13.8) $P=0.009$ ). However, no significant difference was found between each age group in the calcaneal SOS. Moreover, multivariate analysis used to identify the significant factors of the experience of fragility fractures using all survey variables as explanatory variables identified age (OR (95\%CI):1.07 (1.01-11.2)) and history of falls during the prior year (OR: 2.89 (1.04-8.02)) as significantly associated with the experience of fragility fractures. We were unable to investigate the site and severity and of fragility fractures and situation caused by fragility fractures. Additional studies must be conducted for replication with other survey items related to fragility fractures in large samples.

We used EQ-5D, which is a non-disease specific instrument for evaluating health-related QOL. In an earlier study, we compared QOL between patients with Dupuytren's disease and subjects without the disorder using EQ-5D [25]. Health-related QOL is apparently an important indicator reflecting the influences of chronic disease, therapeutic management, and disabilities. Earlier studies evaluated the relation between health-related QOL and QUS parameters. Tashiro et al. assessed the relation between health-related QOL evaluated by Short-Form 36 Health Survey and QUS parameters in 88 women with mean age of 57 years [26]. Multiple regression analysis conducted for their study revealed that BMI, physical function, and role limitations caused by emotional problems were factors associated with higher bone mineral contents. Their results suggest the importance of the psychological state in osteoporosis patients. From results of analysis of 1,812 postmenopausal women, Gonnelli et al. reported that the stiffness index obtained using QUS at the calcaneus is negatively associated with both the Quality of life questionnaire of the European Foundation for Osteoporosis (QUALEFFO) total score and all domains of the QUALEFFO-41 in stepwise multiple logistic regression [8]. Stepwise linear regression analysis conducted for our study revealed Euro QOL-VAS as a significant predictor of calcaneal SOS. Our results suggest a positive cycle that includes physical activity and muscle strength and bone health and QOL. Increased physical activity might bring about gain of muscle strength and improvement of bone health. Consequently, increased physical performance might cause progress of QOL. Selfassessment of health-related QOL might indirectly reflect the bone status. It is apparently important to try living a full life to prevent decreasing bone status.

Light and moderate alcohol consumption was positively associated with bone strength, but heavy alcohol intake negatively affects bone structure [27, 28]. Tucker et al. reported that consuming one portion of beer or other alcoholic beverage per day was positively associated with hip and spine BMD [27]. Ilich et al. reported positive significance for the relation between light alcohol consumption ( $8 \mathrm{~g}$ alcohol/day) and lumbar spine and whole body BMD in 
postmenopausal women [28]. In our study, stepwise linear regression analysis revealed drinking (alcohol) history ( $\beta$ coefficient $=0.26, p=.006$ ) as a significant contributor to SOS among men, but not among women. Results show that $40.6 \%(28 / 69)$ of men reported a history of alcohol intake, but only $6.9 \%$ (10/145) of women did. The low relative frequency of female participants reporting a history of alcohol consumption might affect the statistical power of the analyses used for this study. Earlier reports have described the relation between smoking and quantitative ultrasound parameters for bone health [29.30]. Bernards et al. demonstrated that current and lifetime smoking are significantly and negatively associated with SOS in both genders and with BUA in women in 343 participants with average age of 36 years [29]. However, Kim et al. demonstrated that smoking has no association with QUS parameters after correction for age and years after menopause for 790 Korean women [30]. In this study, the participants judged to have osteoporosis by QUS showed no significant association with a smoking habit. The relation between smoking and QUS parameters apparently remains controversial.

Some reports have described the predictors of BMD and bone quality using other metrics [31, 32]. Tingart et al. measured the cortical thickness at two levels of the proximal humeral diaphysis and evaluated the BMD for the humeral head, the surgical neck, the greater tuberosity, and lesser tuberosity using dual-energy x-ray absorptiometry. They reported a significant positive correlation between the cortical thickness and BMD for each region of interest [31]. Nicks et al. matched younger ( 44 women of $<50$ years and 57 men of $<50$ years) and older subjects ( 44 women of $\geq 50$ years and 57 men of $\geq 50$ years) for areal BMD at the ultradistal radius and assessed possible differences in trabecular and cortical microstructure using high-resolution peripheral quantitative computed tomography. They reported that no sex-specific differences was found in trabecular microstructural parameters. However, significant differences were found in the cortical microstructure (all $p<.05$ ) in these matched subjects. Older women and men had increased cortical porosity (by $91 \%$ and $56 \%$, respectively), total cortical pore volume (by $77 \%$ and $61 \%$, respectively), and mean cortical pore diameter (by $9 \%$ and $8 \%$, respectively) compared with those of younger subjects [32]. These results suggest new metrics as predictors of bone condition. Nevertheless, further studies must be conducted elucidate the predictors of BMD and bone quality with other metrics in multiple factorial analysis.

Our study had several limitations. First, the sample size used for this study was small. We assessed only those subjects who had completed all survey items, which might explain the small number of participants in this study. Second, we were unable to evaluate the muscle power of lower extremities. Rikkonen et al. reported from multiple logistic regression analysis that grip strength and leg extension strength are significantly associated with femoral neck osteoporosis for postmenopausal women [33]. Third, we were unable to assess the association between weight-bearing exercise and calcaneal SOS. Yung et al. reported that weight-bearing exercise such as soccer and dancing more strongly affected the maximization of peak bone mass than non-weight bearing exercise such as swimming [34]. Further studies must be conducted to elucidate the quantitative ultrasound assessment with multiple related factors in the general population.

\section{CONCLUSION}

Significant association was found between non-dominant handgrip strength and osteoporosis assessed by QUS of calcaneus in multiple logistic regression analysis. In men, stepwise linear regression analysis revealed non-dominant handgrip, drinking (alcohol) history, and Euro QOL VAS as significant contributors to increased SOS. In women, stepwise linear regression analysis revealed non-dominant key pinch and Euro QOL VAS as significant contributors to increased SOS. In all participants, non-dominant key pinch and Euro QOL VAS were found to be predictors of calcaneal SOS. Intrinsic muscle of the hand and health outcomes judged for individual respondents might be useful as tools for bone health assessment. Our results suggest that muscle strengthening of extrinsic and intrinsic muscle of hand and living a life full of activity are important metrics of bone quality.

\section{LIST OF ABBREVIATIONS}

$\begin{array}{lll}\text { BMD } & = & \text { Bone mineral density } \\ \text { BMI } & = & \text { Body mass index } \\ \text { BUA } & = & \text { Broadband under attenuation } \\ \text { GLFS } & = & \text { Geriatric Locomotive Functional Scale } \\ \text { JOA } & = & \text { Japanese Orthopaedic Association (JOA) } \\ \text { QOL } & = & \text { Quality of life } \\ \text { QUS } & = & \text { Quantitative ultrasound }\end{array}$




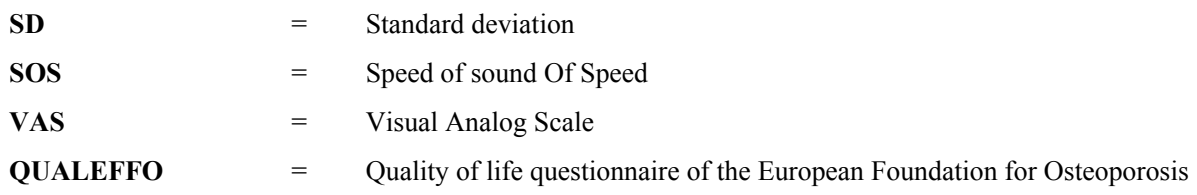

\section{CONFLICT OF INTEREST}

The authors confirm that this article content has no conflict of interest.

\section{ACKNOWLEDGEMENTS}

The authors thank the participants and the medical staff and public health nurses of the regional health center for their assistance and support in this study.

\section{REFERENCES}

[1] Arai H, Ouchi Y, Toba K, et al. Japan as the front-runner of super-aged societies: Perspectives from medicine and medical care in Japan. Geriatr Gerontol Int 2015; 15(6): 673-87.

[http://dx.doi.org/10.1111/ggi.12450] [PMID: 25656311]

[2] Orimo H, Nakamura T, Hosoi T, et al. Japanese 2011 guidelines for prevention and treatment of osteoporosisexecutive summary. Arch Osteoporos 2012; 7: 3-20. [http://dx.doi.org/10.1007/s11657-012-0109-9] [PMID: 23203733]

[3] Gullberg B, Johnell O, Kanis JA. World-wide projections for hip fracture. Osteoporos Int 1997; 7(5): 407-13. [http://dx.doi.org/10.1007/PL00004148] [PMID: 9425497]

[4] Frost ML, Blake GM, Fogelman I. Quantitative ultrasound and bone mineral density are equally strongly associated with risk factors for osteoporosis. J Bone Miner Res 2001; 16(2): 406-16. [http://dx.doi.org/10.1359/jbmr.2001.16.2.406] [PMID: 11204441]

[5] Blanchet C, Giguère $\mathrm{Y}$, Prudhomme $\mathrm{D}$, et al. Leisure physical activity is associated with quantitative ultrasound measurements independently of bone mineral density in postmenopausal women. Calcif Tissue Int 2003; 73(4): 339-49. [http://dx.doi.org/10.1007/s00223-002-1091-9] [PMID: 12874703]

[6] Nagai A, Tajika T, Yamamoto A, Okura C, Kanazawa S, Takagishi K. Relations between quantitative ultrasound assessment of calcaneus and grip and key pinch power in Japanese mountain village residents. J Orthop Surg (Hong Kong) in press

[7] Nakamura K. A super-aged society and the locomotive syndrome. J Orthop Sci 2008; 13(1): 1-2. [http://dx.doi.org/10.1007/s00776-007-1202-6] [PMID: 18274847]

[8] Gonnelli S, Caffarelli C, Tanzilli L, et al. Relationship between quantitative ultrasound parameters at the calcaneus and health-related quality of life in postmenopausal Italian women: the FEDRO study. Calcif Tissue Int 2013; 93(6): 487-94. [http://dx.doi.org/10.1007/s00223-013-9769-8] [PMID: 23912952]

[9] Seichi A, Hoshino Y, Doi T, Akai M, Tobimatsu Y, Iwaya T. Development of a screening tool for risk of locomotive syndrome in the elderly: the 25-question Geriatric Locomotive Function Scale. J Orthop Sci 2012; 17(2): 163-72. [http://dx.doi.org/10.1007/s00776-011-0193-5] [PMID: 22222445]

[10] Group E. EuroQola new facility for the measurement of health-related quality of life. Health Policy 1990; 16(3): 199-208. [http://dx.doi.org/10.1016/0168-8510(90)90421-9] [PMID: 10109801]

[11] Tsuchiya A, Ikeda S, Ikegami N, et al. Estimating an EQ-5D population value set: the case of Japan. Health Econ 2002; 11(4): 341-53. [http://dx.doi.org/10.1002/hec.673] [PMID: 12007165]

[12] Takaishi Y, Okamoto Y, Ikeo T, et al. Correlations between periodontitis and loss of mandibular bone in relation to systemic bone changes in postmenopausal Japanese women. Osteoporos Int 2005; 16(12): 1875-82. [http://dx.doi.org/10.1007/s00198-005-1955-8] [PMID: 16027956]

[13] Miura S, Saavedra OL, Yamamoto S. Osteoporosis in urban post-monopausal women of the Philippines: prevalence and risk factor. Arch Osteoporos 2008; 3: 17-24. [http://dx.doi.org/10.1007/s11657-008-0018-0]

[14] Chin KY, Soelaiman IN, Mohamed IN, Ibrahim S, Wan Ngah WZ. The effects of age, physical activity level, and body anthropometry on calcaneal speed of sound value in men. Arch Osteoporos 2012; 7: 135-45. [http://dx.doi.org/10.1007/s11657-012-0091-2] [PMID: 23225291]

[15] Babaroutsi E, Magkos F, Manios Y, Sidossis LS. Body mass index, calcium intake, and physical activity affect calcaneal ultrasound in healthy Greek males in an age-dependent and parameter-specific manner. J Bone Miner Metab 2005; 23(2): 157-66. [http://dx.doi.org/10.1007/s00774-004-0555-6] [PMID: 15750695]

[16] Lang T, Streeper T, Cawthon P, Baldwin K, Taaffe DR, Harris TB. Sarcopenia: etiology, clinical consequences, intervention, and assessment. Osteoporos Int 2010; 21(4): 543-59. [http://dx.doi.org/10.1007/s00198-009-1059-y] [PMID: 19779761] 
[17] Yoshimura N, Oka H, Muraki S, et al. Reference values for hand grip strength, muscle mass, walking time, and one-leg standing time as indices for locomotive syndrome and associated disability: the second survey of the ROAD study. J Orthop Sci 2011; 16(6): 768-77. [http://dx.doi.org/10.1007/s00776-011-0160-1] [PMID: 21975521]

[18] Sinaki M, Fitzpatrick LA, Ritchie CK, Montesano A, Wahner HW. Site-specificity of bone mineral density and muscle strength in women: job-related physical activity. Am J Phys Med Rehabil 1998; 77(6): 470-6. [http://dx.doi.org/10.1097/00002060-199811000-00002] [PMID: 9862531]

[19] Aydin G, Atalar E, Keleş I, et al. Predictive value of grip strength for bone mineral density in males: site specific or systemic? Rheumatol Int 2006; 27(2): 125-9.

[http://dx.doi.org/10.1007/s00296-006-0178-4] [PMID: 16932964]

[20] Tajika T, Kobayashi T, Yamamoto A, et al. Relationship between grip, pinch strengths and anthropometric variables, types of pitch throwing among Japanese high school baseball pitchers. Asian J Sports Med 2015; 6(1): e25330. [http://dx.doi.org/10.5812/asjsm.25330] [PMID: 25883777]

[21] Lanyon LE. Using functional loading to influence bone mass and architecture: objectives, mechanisms, and relationship with estrogen of the mechanically adaptive process in bone. Bone 1996; 18(1)(Suppl.): 37S-43S [http://dx.doi.org/10.1016/8756-3282(95)00378-9] [PMID: 8717546]

[22] Muramoto A, Imagama S, Ito Z, Hirano K, Ishiguro N, Hasegawa Y. Physical performance tests are useful for evaluating and monitoring the severity of locomotive syndrome. J Orthop Sci 2012; 17(6): 782-8. [http://dx.doi.org/10.1007/s00776-012-0283-z] [PMID: 22961424]

[23] Ou LC, Sun ZJ, Chang YF, et al. Epidemiological survey of quantitative ultrasound in risk assessment of falls in middle-aged and elderly people. PLoS One 2013; 8(8): e71053. [http://dx.doi.org/10.1371/journal.pone.0071053] [PMID: 23951077]

[24] Lee SH, Dargent-Molina P, Bréart G. Risk factors for fractures of the proximal humerus: results from the EPIDOS prospective study. J Bone Miner Res 2002; 17(5): 817-25. [http://dx.doi.org/10.1359/jbmr.2002.17.5.817] [PMID: 12009012]

[25] Tajika T, Kobayashi T, Kaneko T, et al. Epidemiological study for personal risk factors and quality of life related to Dupuytrens disease in a mountain village of Japan. J Orthop Sci 2014; 19(1): 64-70. [http://dx.doi.org/10.1007/s00776-013-0478-y] [PMID: 24129389]

[26] Tashiro A, Kakuta H, Tanaka N, Takeuchi Y. Relationship between health-related quality of life domains and bone status in postmenopausal Japanese women. Menopause 2006; 13(5): 846-9. [http://dx.doi.org/10.1097/01.gme.0000227024.96686.c2] [PMID: 16894337]

[27] Tucker KL, Jugdaohsingh R, Powell JJ, et al. Effects of beer, wine, and liquor intakes on bone mineral density in older men and women. Am J Clin Nutr 2009; 89(4): 1188-96.

[http://dx.doi.org/10.3945/ajcn.2008.26765] [PMID: 19244365]

[28] Ilich JZ, Brownbill RA, Tamborini L, Crncevic-Orlic Z. To drink or not to drink: how are alcohol, caffeine and past smoking related to bone mineral density in elderly women? J Am Coll Nutr 2002; 21(6): 536-44. [http://dx.doi.org/10.1080/07315724.2002.10719252] [PMID: 12480799]

[29] Bernaards CM, Twisk JW, Snel J, van Mechelen W, Lips P, Kemper HC. Smoking and quantitative ultrasound parameters in the calcaneus in 36-year-old men and women. Osteoporos Int 2004; 15(9): 735-41. [http://dx.doi.org/10.1007/s00198-004-1603-8] [PMID: 14997288]

[30] Kim CH, Kim YI, Choi CS, et al. Prevalence and risk factors of low quantitative ultrasound values of calcaneus in Korean elderly women. Ultrasound Med Biol 2000; 26(1): 35-40.

[http://dx.doi.org/10.1016/S0301-5629(99)00126-X] [PMID: 10687790]

[31] Tingart MJ, Apreleva M, von Stechow D, Zurakowski D, Warner JJ. The cortical thickness of the proximal humeral diaphysis predicts bone mineral density of the proximal humerus. J Bone Joint Surg Br 2003; 85(4): 611-7. [http://dx.doi.org/10.1302/0301-620X.85B4.12843] [PMID: 12793573]

[32] Nicks KM, Amin S, Atkinson EJ, Riggs BL, Melton LJ III, Khosla S. Relationship of age to bone microstructure independent of areal bone mineral density. J Bone Miner Res 2012; 27(3): 637-44. [http://dx.doi.org/10.1002/jbmr.1468] [PMID: 22095490]

[33] Rikkonen T, Sirola J, Salovaara K, et al. Muscle strength and body composition are clinical indicators of osteoporosis. Calcif Tissue Int 2012; 91(2): 131-8.

[http://dx.doi.org/10.1007/s00223-012-9618-1] [PMID: 22733383]

[34] Yung PS, Lai YM, Tung PY, et al. Effects of weight bearing and non-weight bearing exercises on bone properties using calcaneal quantitative ultrasound. Br J Sports Med 2005; 39(8): 547-51. [http://dx.doi.org/10.1136/bjsm.2004.014621] [PMID: 16046341] @ Tajika et al.; Licensee Bentham Open 